NASA

Technical Memorandum 83716

AIAA-84-1500
USAAVSCOM

Technical Report 84-C-8

\title{
An Analytical Method To Predict Efficiency of Aircraft Gearboxes
}

Neil E. Anderson

Propulsion Laboratory

AVSCOM Research and Technology Laboratories

Lewis Research Center

Cleveland, Ohio

and

Stuart H. Loewenthal

Lewis Research Center

Cleveland, Ohio

and

Joseph D. Black

Allison Gas Turbine Operations

Indianapolis, Indiana

Prepared for the

Twentieth Joint Propulsion Conference

cosponsored by the AIAA, SAE, and ASME

Cincinnati, Ohio, June 11-13, 1984

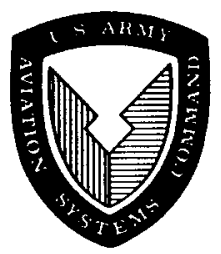




\author{
Nei] E. Anderson* \\ Propulsion Laboratory \\ AVSCOM Research and Technology Laboratories \\ Lewis Research Center \\ Cleveland, Ohio \\ Stuart H. Loewenthal \\ National Aeronautics and Space Administration \\ Lewis Research Center \\ Cleveland, Ohio \\ and \\ Joseph D. Black \\ Allison Gas Turbine Operations \\ Indianapolis, Indiana
}

\section{Abstract}

A spur gear efficiency prediction method previously developed by the authors was extended to include power loss of planetary gearsets. A friction coefficient model was developed for MIL-L-7808 oil based on disc machine data. This combined with the recent capability of predicting losses in spur gears of nonstandard proportions allows the calculation of power loss for complete aircraft gearboxes that utilize spur gears. The method was applied to the T56/501 turboprop gearbox and compared with measured test data. Bearing losses were calculated with large scale computer programs. Breakdowns of the gearbox losses point out areas for possible improvement.

\section{Nomenclature}

a

AR

C

$c_{1}$ to $c_{6}$

e

ER

$F_{R}$

$\mathrm{FS}_{\mathrm{S}}$

$\mathscr{F}$

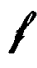

G

$H_{H}$

h

K

addendum ratio

center distance, $m$ (in.)

constants of proportionality

tool shift, m (in.)

tool shift ratio

rolling traction force, $N$ (1bf)

sliding force, $N$ (1bf)

face width of tooth, m (in.)

coefficient of friction

dimensionless material parameter, $E^{\prime} \alpha$

dimensionless film thickness

(eq. (4))

isothermal central film thickness, m (in.)

gear capacity factor $K=\frac{w\left(m_{g}+1\right)-}{\mathscr{F} D_{p} m_{g}}$

*Currently with Allison Gas Turbine Operations. k

$\mathrm{m}_{\mathrm{g}}$

N

n

$\mathrm{p}_{\mathrm{b}}$

$\mathrm{P}_{\mathrm{R}}$

PS

PW

$\mathscr{P}$

R

ellipticity parameter

gear ratio, $\mathrm{N}_{\mathrm{g}} / \mathrm{N}_{\mathrm{p}}$

number of gear teeth

rotational speed, rpm

base pitch, m (in.)

power loss due to rolling traction, kW (hp)

power loss due to tooth sliding $\mathrm{kW}$ (hp)

power loss due to windage, kW (hp)

diametral pitch

pitch circle radius or radius in general, m (in.)

maximum Hertz stress, GPa

sliding velocity to rolling velocity ratio

lubricant inlet temperature

dimensionless speed parameter

surface velocity, $\mathrm{m} / \mathrm{sec}(\mathrm{in} / \mathrm{sec})$

sliding velocity, $v_{g}-v_{p}$, $\mathrm{m} / \mathrm{sec}(\mathrm{in} / \mathrm{sec})$

rolling velocity, $v_{g}+v_{p}$, $\mathrm{m} / \mathrm{sec}$ (in/sec)

dimensionless load parameter, $F_{H} / E^{\prime} R_{X}^{2}$

gear contact normal load, N (Ibf)

path of contact distances, $m(i n$.

Greek
dimensionless ratio of $f i l m$ thickness to composite surface roughness


Subscripts:

c

9

i

$\mathrm{p}$

plv

R

$r$

S

$\mathbf{t}$

Superscripts:

$\begin{array}{ll}\left(^{-}\right) & \text {average value } \\ * & \text { evaluate at } s=0.35\end{array}$

Introduction

Increasing fuel prices in the last decade have stimulated interest in finding ways to reduce fuel consumption for aircraft transportation. The significant fuel efficiency advantages that turboprop propulsion systems offer over turbofan systems at equivalent Mach numbers has long been recognized. Turbof an systems, however, have had the advantage in higher Mach number operation and lower noise levels in the past. Recently emphasis has been placed on a propulsion system that would overcome some of the disadvantages of the turboprop system. This system, know as the propfan, allows aircraft to cruise at Mach numbers of 0.8 with significantly higher efficiencies than modern turbofans. These advanced propfans will very likely require a gearbox to reduce the speed between the power section and the propfan. Improving the efficiency of this gearbox would provide further fuel consumption savings. For the current T56/501 engine, each 0.1 percent improvement in the effective gearbox efficiency results in approximately a 700000 annual fuel savings for the user.
Lubrication system designs also benefit from reduced gearbox heat generation. Reducing gearbox heat generation permits the oil flow to be reduced without affecting the temperature rise across the gearbox. Lower oil flow rates reduce oil pump energy losses and reduce windage/churning losses associated with the improved air/oil environment. Reduced oil flow rate requirements also allow the weight and size of the lubrication system to be reduced. Smaller tanks, lines, passages, filters, pumps, and on-board oil quantities can be employed. Further, reduced gearbox heat generation allows air/oil cooler size and weight to be reduced. Smaller coolers result in lower aircraft drag which leads to better specific fuel consumption. For high Mach number aircraft, such as the propfan, these drag reduction benefits are significant.

Gearbox efficiency improvements can provide significant benefits. Gearbox efficiency optimization has not normally been included in the aircraft gearbox design methodology in the past, however, due to the lack of a technique that could assess the many design variables $[1,2]$. In $[3,4]$ a technique was described that included the major design variables required for standard involute spur gears. In [5] this technique was extended to include nonstandard spur gears. Nonstandard geometries included modified addendums, tooth thickness variations and operation on nonstandard gear centers either by design or as a function of operating conditions.

In order to analyze the T56/501 gearbox for efficiency in this investigation the method of [ 3 to 5] required modifications to include internal spur gear geometry and the effects of planetary motion. Additionally, a friction coefficient model was required for the MIL-L-7808 oil used in the gearbox testing. With these new tools an examination of the various losses in the gearbox could be made.

\section{Transmission Power Loss Analysis}

\section{Gear Power Loss Equations}

The method utilized here for calculation of power loss was described in detail in $[3,4]$ as applied to spur gears of standard proportions and in [5] for gears of nonstandard proportions. It is applicable to spur gears which are jet or splash lubricated. Churning losses of gears running submerged in oil are not considered. The analysis considers sliding losses, which are the result of friction forces developed as the teeth slide across each other, rolling losses resulting from the formation of an elastohydrodynamic (EHD) film and windage losses of both gears spinning in an oily atmosphere.

Sliding and rolling losses were evaluated by numerically integrating the instantaneous values of these losses across the path of contact. The friction coefficient used to calculate sliding loss [3-5] was based on disk machine data generated by Benedict and Kelley[6] for mineral oils. This friction coefficient expression is considered 
to be applicable in the EHD Tubrication regime where some asperity contact occurs, that is, for lambda ratios less than two ( lambda = ratio of minimum EHD film thickness to composite surface roughness). The Benedict and Kelley friction coefficient was useful for comparing gear geometry variations when lubricant type is not a variable. In [7] lubricant type was found to have a significant effect on the efficiency of an $\mathrm{OH}-58$ helicopter transmission. The effect of using eleven types of oil (defined in table I) is shown in Fig. 1. Thus, it is important to utilize a friction coefficient model that simulates the type of oil used in the transmission tests. A model was developed for a MIL-L-7808 type oil and is described in a later section.

In [3] rolling losses were based on disk machine data generated by Crook [8]. Crook found that the rolling loss was simply a constant value multiplied by the EHD central film thickness. Gear tooth film thickness was calculated by the method of Hamrock[9] and adjusted for thermal effects using Cheng's thermal reduction factor 10$]$. At high pitch line velocities isothermal equations such as Hamrock's will predict abnormally high film thickness since shear heating is not considered. Cheng's thermal reduction factor will account for the inlet shear heating and reduce the film thickness accordingly. Inlet starvation effects are not considered.

The equations developed in [3-5] are reviewed here and extended to include planetary gearsets. Figure 2(a) shows the tooth load distribution utilized in this analysis for gears with contact ratios between one and two. The teeth are assumed to be perfectly rigid and perfectly machined thus creating abrupt changes in tooth load as one or two teeth come into contact. The effect of contact ratio can be seen in this figure as the proportion of time that the load is shared by two teeth relative to that for one. Mesh two is being analyzed from start to finish but there are power loss contributions from mesh one and three that must be considered as well. Figure 2(b) shows the analogous load distribution for contact ratios between two and three where either two or three teeth share the load. Here the tooth loads are lower due to the greater number of teeth sharing the load but now there are five mesh contacts contributing to the gearset power loss over one tooth mesh cycle. Extension of the analysis to high contact ratio (HCR) gears was mainly a matter of being able to specify the additional changes in load as shown in Fig. 2(b). All basic equations other than the calculation of load were identical.

Sliding force - The instantaneous frictional force due to sliding of two gear teeth against each other is

$$
\mathrm{F}_{\mathrm{S}}(\mathrm{X})=f(\mathrm{x})_{\mathrm{w}}(\mathrm{x})
$$

The friction coefficient is normally calculated by the method of Benedict and Kelley[6] for mineral oils. A new friction coefficient model for the MIL-L-7808 oil used in the T56/501 gearbox appears later in this report.

$$
\begin{aligned}
f_{B K}(X) & =0.0127 \log \frac{\frac{C_{1} w(x)}{\mathscr{F}}}{\mu\left[v_{S}(x)\right]\left[V_{T}(x)\right]^{2}} \\
C_{1} & =29.66 \text { (SI units) } \\
& =45.94 \text { (U.S. customary units) }
\end{aligned}
$$

Rolling force - The instantaneous force due to buitd up of the EHD film is

$$
\begin{gathered}
F_{R}(X)=C_{2} h(X)_{\varphi_{t}}(X)_{F} \\
C_{2}=9.0 \times 10^{7} \text { (SI units) } \\
=1.3 \times 10^{4} \text { (U.S. customary units) }
\end{gathered}
$$

The gear contact film thickness is calculated by the method of Hamrock and Dowson [9]

$H_{H}=\frac{h}{R_{X}}=2.69 u^{0.67}{ }_{G} 0.53 W^{-0.067}\left(1-0.61 \mathrm{e}^{-0.73 k}\right)$

A thermal reduction factor, $\varphi$ t developed in [10] is used to limit $h$ at high speeds.

Sliding and rolling power loss - The instantaneous sliding and rolling power loss cán be expressed as

$$
\begin{aligned}
& P_{S}(x)=C_{3} V_{S}(x) F_{S}(x) \\
& P_{R}(X)=C_{3} V_{T}(x) F_{R}(x) \\
& c_{3}=10^{-3} \text { (SI units) } \\
& =1.515 \times 10^{4} \text { (U.S. customary units) }
\end{aligned}
$$

Average sliding and rolling power loss for contact ratios between one and two - The path of contact is divided into three sections corresponding to the changes in the normal load. The multiplication factors are due to the effects of load sharing as shown in Fig. 2(a).

$$
\begin{aligned}
\bar{P}_{S}+\bar{P}_{R}=\frac{1}{x_{4}-x_{1}}\left\{2 \int_{X_{1}}^{x_{2}}\left[P_{S}(x)+P_{R}(x)\right] d x\right. \\
+\int_{X_{2}}^{x_{3}}\left[P_{S}(x)+P_{R}(x)\right] d x \\
+2 \int_{x_{3}}^{x_{4}}\left[P_{S}(x)+P_{R}(x)\right] d x
\end{aligned}
$$


Average sliding and rolling power loss for contact ratios between two and three - Here the path of contact is divided into five sections due to the more frequent changes in load.

$$
\begin{aligned}
& P_{S}+P_{R}=\frac{1}{X_{6}-x_{1}}\left\{3 \int_{X_{1}}^{x_{2}}\left[P_{S}(x)+P_{R}(x)\right] d x\right. \\
& +2 \int_{x_{2}}^{x_{3}}\left[P_{S}(x)+P_{R}(x)\right] d x+ \\
& +3 \int_{X_{3}}^{x_{4}}\left[P_{S}(x)+P_{R}(x)\right] d x \\
& +2 \int_{x_{4}}^{x_{5}}\left[p_{S}(x)+p_{R}(x)\right] d x+ \\
& +3 \int_{x_{5}}^{x_{6}}\left[p_{S}(x)+p_{R}(x)\right] d x
\end{aligned}
$$

Windage Loss Expressions -

$$
\begin{aligned}
& P_{W, g}=C_{4}\left(1+2.3 \frac{\mathscr{F}}{R_{g}}\right)\left(\frac{n_{p}}{m_{g}}\right)^{2.8} \\
& \quad \times R_{g}^{4.6}\left(0.028 \mu+C_{5}\right)^{0.2} \\
& P_{W, p}=C_{4}\left(1+2.3 \frac{\mathscr{F}}{R_{p}}\right) n_{p}^{2.8} R_{p}^{4.6}\left(0.028 \mu+C_{5}\right)^{0.2}
\end{aligned}
$$

where

$$
\begin{aligned}
C_{4} & =2.82 \times 10^{-7} \text { (SI units) } \\
& =4.05 \times 10^{-13} \text { (U.S. customary units) } \\
C_{5} & =0.019 \text { (SI units) } \\
& =2.86 \times 10^{-9} \text { (U.S. customary units) }
\end{aligned}
$$

Modification of Equations for Nonstandard Involute Spur Gears

The additional features included in [5] that allowed calculation of nonstandard gears were: (1) addendum modifications maintaining pitch circle tooth thickness (modified cutter addendum); (2) addendum modifications accompanied by changes in pitch circle tooth thickness (tool shift); and (3) operation of gears on nonstandard center distances. The effects of addendum modification on tooth shape are shown in Fig. 3 .

Pinion and gear addendums were specified independent $7 y$ as follows:

$$
a=(A R+E R) / P
$$

where $A R=$ addendum ratio $=(a)(P)$ when $E R=0$

$E R=$ tool shift ratio $=(e)(P)$

$\mathrm{e}=$ actual tool shift

The affect of modified addendum on the eff $i_{-}$ ciency equations was to alter the starting and end points of contact. This in turn affects the contact ratio. All other equations apply with no modification.

The gear geometry equations were also modified to account for operation at nonstandard center distances following Khiralla[11]. The previously developed efficiency equations of [3] were still used but the operating pressure angle and the operating pitch diameter were used in place of the nominal values. The effect of increasing the center distance from standard is to increase both the pressure angle and the pitch diameter. This results in increased backlash and lower contact ratio. Tool shift can be used to remove the backlash but the changes in pressure angle and pitch diameter remain.

\section{Calculation of Power Loss in a Planetary Gearset}

The two differences between the planetary gearset and the external mesh already analyzed are internal gear geometry and altered rotational speeds due the carrier rotation. The internal gear geometry will be addressed first.

Since the internal involute spur gear is very similar to its external counterpart the changes required for the analysis of power loss are minor. These changes include new expressions for: (1) points along the path of contact, (2) radius of curvature of the teeth and (3) sliding and rolling velocities. The power loss Eqs. 6 and 7 are still applicable when used with the geometry of the internal gear.

In Fig. 4(a) the path of contact of an internal gear is shown with the rigid tooth load distribution of Fig. 2(a) superimposed. Contact starts at the intersection of the tip diameter of the internal gear with the path of contact at $x 1$. The path of contact is tangent to the base circles of the two gears. Contact ends at the intersection of the tip diameter of the external gear with the path of contact at $\times 4$. The intermediate points $\times 2$ and $X 3$ are one base pitch length from the endpoints. The equations required to calculate these points follow:

$$
\begin{gathered}
X 1=\sqrt{R_{i r}^{2}-R_{b r}^{2}} \\
X 2=x 4-p_{b} \\
X 3=x 1+p_{b}
\end{gathered}
$$




$$
\begin{gathered}
X 4=\sqrt{R_{r}^{2}-R_{b r}^{2}}-\sqrt{R_{p}^{2}-R_{b p}^{2}}+\sqrt{R_{o p}^{2}-R_{b p}^{2}} \\
X P=\sqrt{R_{r}^{2}-R_{b r}^{2}}
\end{gathered}
$$

The radii of curvature of the teeth change as the point of contact moves along the path of contact. The radius of curvature of the internal gear is I2X and the external gear is I1X.

$$
R_{c p}=X
$$

$R_{c g}=x-\left(R_{r}-R_{p}\right) \sin \phi$

A velocity diagram for the internal mesh is shown in Fig. $4(\mathrm{~b})$. $V_{r}$ and $V_{p}$ are the absolute velocities of the gears at point $X$ for the internal and external gears respectively. The absolute velocities can be broken into velocities along the tooth surface, $v t$, and velocities perdpendicular to the tooth surface, $V p$. Sliding velocity is defined as the difference in the tangential velocities while rolling velocity is the sum. The velocity components are calculated as a function of the roll angles of the gears as follows:

$$
\begin{aligned}
V_{S} & =V_{t p}-V_{t r} \\
& =V_{p l v}\left(\sin \psi_{p}-\sin \psi_{r}\right) \\
V_{T} & =V_{t p}+V_{t r} \\
& =V_{p l v}\left(\sin \psi_{p}-\sin \psi_{r}\right)
\end{aligned}
$$

where

$$
\Psi_{p}=\tan ^{-1}\left[(x-C \sin \phi) / R_{b p}\right]
$$

and

$$
\psi_{r}=\tan ^{-1}\left[X / R_{b r}\right]
$$

By using these values in Eqs. (6) and (7), power loss of the internal mesh can be found.

To account for the rotation of the carrier in a $\mathrm{planetary}$ gearset the rotational speeds of the sun gear and planet gear in each of their meshes were modified following Glover[12]. The angular speed of tooth engagement is the gear speed that would be obtained if the carrier was stationary. In this configuration the sun/planet speed was the sun gear absolute speed less the carrier speed. The planet/ring mesh speed was found by setting the ring speed equal to the negative of the carrier speed. The torque balance is not modified and thus loads are identical for a fixed or rotating carrier. Rotational speeds for other planetary configurations can be found in [12].

\section{Calculation of Bearing Power Loss}

Bearing power losses at various flight loading conditions were calculated with large scale computer programs, The programs used were NASA versions of CYBEAN 13] for cylinder roller bearings, SPHERBEAN[14] for the planet bearing and SHABERTH[15] for the prop thrust bearing. These programs calculate heat generation at the many contacting surfaces within the bearing. Known operating temperatures were input variables along with detailed bearing geometry. An internal lubricant model was used for the MIL-L-7808 type lubricant. These large programs are designed to perform calculations for bearings that are carrying significant load. At light loads when the number of loaded rolling elements becomes equal to one, numerical difficulties arise and the results are not accurate. Thus these programs cannot be used for the spin (no-load) calculation. Instead the Harris[16] equations were used to calculate the spin losses.

\section{Calculation of Power Loss in 0il Pumps}

0 il pump loses were calculated by conventional methods using oil flow rate, pressure head and pump efficiency. The main oil supply pump efficiency was set equal to 25 percent based on past experience. The two scavenge pumps were rated at 20 percent efficiency due to the aerated oil that it must pump. Losses were proportioned with speed of rotation to the third power.

\section{Friction Coefficient for Mil-L-7808 Type $0 i 1$}

A breakdown of the gear mesh powe loss components in [3] indicates that the sliding friction loss is a major loss component at moderate to high loads, particularly at the lower meshing speeds. Thus an accurate description of the friction characteristics of the oil in question is vital for accurate loss predictions. In the past the authors relied on the Benedict and Kelley friction coefficient model[6] for mineral oils to provide an engineering estimate of power loss. However in reviewing published friction coefficient data for several different MIL-L-7808 type oils $[17,18]$ it was apparent the MIL-L-7808 oil's friction coeff $i-$ cient was several times smaller than that predicted by the Benedict and Kelley model at comparable operating conditions. In view of this it was descided that a friction model based on a regression analys is of the MIL-L-7808 friction data appearing in [17] would provide a better estimate of gear sliding losses.

The friction data appearing in [17] was generated on a twin disc machine over a wide range of conditions for one type of MIL-L-7808 oil. Maximum contact pressures ranged from 0.69 to $1.03 \mathrm{GPa}$, rolling speeds from 11.4 to $46.3 \mathrm{~m} / \mathrm{s}$, oil temperatures from 23 to $71 \mathrm{deg}$. $C$, and slide to roll ratios $\left(2 V_{S} / V_{T}\right)$ from 0 to 0.35 . A total of 41 separate friction/slip curves were analyzed. The following regression equation was obtained: 
for $0 \leq S \leq 0.35$

$$
\begin{array}{r}
f=f_{78}=0.00209+0.01696 \mathrm{P}_{\max }-3.553 \times 10^{-5} \mathrm{v} \\
+8.739 \times 10^{-5} \mathrm{~T}+6.998 \times 10^{-4} \ln (\mathrm{S}) \\
+0.01734(\mathrm{~S})-0.0173(\mathrm{~S})^{2}
\end{array}
$$

where

$$
\begin{aligned}
\mathrm{P}_{\max } & =\text { maximum Hertz stress, } \mathrm{GPa} \\
\mathrm{V} & =\text { sum velocity, } \mathrm{m} / \mathrm{sec} \\
\mathrm{T} & =\text { lubricant inlet temperature, deg } \\
\mathrm{S} & \text { Celsius } \\
\mathrm{S} & \text { slide/roll ratio }=2 \mathrm{~V}_{\mathrm{S}} / \mathrm{V}_{\mathrm{T}}
\end{aligned}
$$

note for steel gears in line contact:

$$
P_{\max }=C_{6} \sqrt{w(X) / F\left(1 / R_{c p}+1 / R_{c g}\right)}
$$

where $c_{6}=1.902 \times 10^{-4}$ (SI units); 2290.6 (U.S. customary units)

The correlation regression coefficient, $R$, for the chove equation is $0.956 . R$ is a measure of both the $f$ it of the regression equation and the consistency of the test data. (An $R$ value of 0 indicates no correlation while and $R$ value of 1 indicates perfect correlation).

High slip region - Unfortunately, the friction data appearing in [17] was limited to intermediate slip values which cover only the region of gear contact near the pitch point. Since slide to roll ratios of 1.0 or greater are not uncommon at gear mesh entry and exit points, it was necessary to extend the friction model to the high slip region.

One approach which could be taken is basically theoretical in nature in which the traction characteristics are thermally modeled $[19,20]$. The problem in applying such a model is that several basic thermal properties of the oil and their variations with temperature and pressure must be known to properly perform the analysis. The other approach, adopted here, is to assume that the degradation of the friction coefficient of the MIL-L-7808 oil with increasing slip approximately follows that found from the Benedict and Kelley experiments with several mineral oils as described by Eq. (21).. While it is recognized that such an approach is clearly less desirable than a full theoretical description of the oil's traction, it does, however, provide an interim engineering approximation until a more complete model can be formulated.

For slide to roll ratios, S, greater than 0.35 , a friction coefficient thermal reduction factor, $\beta$, was introduced to modify the friction coefficient found from eq. 20 at $S=0.35$.

Thus for $S>0.35$

$$
f={ }^{\mathrm{B}} \ell^{*}
$$

where $p^{t}=$ friction coefficient found from eq. 20 at $S=0.35$

and

$$
B=\left.\frac{\ell_{\mathrm{BK}}}{\ell_{\mathrm{BK}}}\right|_{\mathrm{S}=0.35}
$$

$$
\beta=\frac{\left[\log \frac{2 C_{1} w(x)}{\mu \mathscr{F S} v_{T}^{3}}\right]}{\left[\log \frac{2 C_{1} w(X)}{\mu \mathscr{F} 0.35 v_{T}^{3}}\right]}
$$

where

$$
\begin{aligned}
& f_{\mathrm{BK}}=\begin{array}{r}
\text { the friction coefficient from the } \\
\text { Benedict and Kelley model }
\end{array} \\
& \left.f_{\mathrm{BK}}\right|_{\mathrm{S}=0.35 \quad \begin{array}{l}
\text { the Benedict and Kelley } \\
\text { friction coefficient model } \\
\text { evaluated at } S=0.35
\end{array}}
\end{aligned}
$$

The predicted variation in $f$ with slide to roll ratio at representative operating conditions appears in Fig. 5. Also, plotted for comparison are some of the test data from [17]. The discontinuity at $S=0.35$ is an artifact of the composite model used here. It's effect on the predicted sliding loss is judged to be extremely small. It is clear from this plot that the effective friction coefficient for the MIL-L-7808 oil analyzed is quite low. Thus the losses due to gear sliding, as will be shown, are expected to be relatively minor.

Other considerations - Two potentially important factors that can influence the friction coefficient model but not included are the effects of lubricant formulation and surface roughness. Although the lubricant tested in [17] and modeled here fits a MIL-L-7808 oil specification, the friction characteristics of the $0 i 1$ can vary significantly with different formulations or brands that meet this specification. This is illustrated in Fig. 1 from [7], where oils C, D, I, and $\mathrm{J}$ all meet the MIL-L-23699 oil specification and yet provide different transmission efficiencies.

Since the viscosities of these oils are ostensibly the same, it is likely that these efficiency differences are largely due to differences in friction. It is interesting to note that oil $\mathrm{C}$ even has a different temperature trend than the other three oils.

Another factor to consider is the effect of surface finish on friction. The data appearing in [17] were generated with hardened steel discs polished to a 2 uin. rms finish. Aircraft gears are generally much rougher than this, although those used in the T56/501 gearbox are relatively 
smooth being honed to about $10 \mu \mathrm{in}$. AA. It is difficult to assess the contribution of asperity friction to the proposed friction model. However, to account for some asperity traction, the proposed model arbitrarily limits the friction coefficient to a minimum of 0.001 . It is interesting to note that relatively large variations in surface roughness (6 to $800 \mu$ in. peak-to-valley roughness) on discs tested in sliding in [21] had remarkably little effect on the measured traction which typically varied from 0.05 to 0.055 at a film thickness of $25 \mu i n$. From this, [21] concludes that the friction mechanism is predominantly a shearing of the oil film rather than metallic or boundary lubrication.

\section{Description of T56/501 Gearbox}

The T56/501 gearbox is used in both military and commercial versions of Lockheed, Grumman and Convair aircraft. As shown in Fig. 6 the first stage of gearing is an offset spur gear mesh. The second stage is a planetary gearset with input to the sun gear and output from the carrier. Five planet gears located on spherical bearing drive the carrier which in turn drives the propeller. Apart from the planet bearing and propeller thrust bearing all other bearings are cylindrical. The seven bearings and five gear types are shown in Fig. 7. Gear and bearing proportions are listed in Table II and III.

An accessory train is driven from the high speed input pinion gear. This drive train supplies power to oil supply pump, scavenge pumps, an alternator, an EDC or hydraulic pump and tachometers. The starter uses this drive train to drive engine during start-up. The accessory drive was analyzed with loads due only to the oil pumps since the efficiency tests did not require accessories. The pinion rear bearing is supported by the rear housing.

\section{Test Stand}

The gearbox power loss data used in this analysis for comparison to the theory were obtained from a cradled dynamometer, no-load testing and back-to-back loaded gearbox testing. The data shown are the results of six tests using four transmissions. The no-load power loss data was obtained by driving the pump shaft with the dynamometers until temperature stabilized at each speed point. A load cell was used to determine the torque required to rotate the transmissions. 0 il heat rejection measurements were also made during these tests. The heat rejection measurement accounts for all losses except scavenge pump losses and heat rejected through the transmission housings.

Power loss at loaded conditions was obtained on a back-to-back gearbox rig using heat rejected to the oil to determine power loss. To account for the scavenge pump loss and heat transfer through the housings the power loss found from the heat loss to the oil was increased in the same proportion as that found in the no-load tests.

Al1 tests were conducted with a MIL-L-7808 lubricant at an inlet temperature of $82.2 \pm 2.7^{\circ} \mathrm{C}$ $(180 \pm 5 \circ \mathrm{F})$. Nominal oil supply pressure was
180 psig, and scavenge pressure was 30-35 psig. Propeller monents and side loads were not applied during efficiency measurements. A constant thrust load of $44480 \mathrm{~N}$ (10 000 lbf) was applied to the propeller shaft however. The gearboxes were tested in a horizontal attitude at sea level pressure.

Accuracy of the efficiency tests was increased by averaging ten oil in and ten oil out thermocouple measurements at the two locations. 0 il flow rate was determined by measuring the change in weight of the oil supply tank during the efficiency calculation period.

\section{Comparison of Theory with Data}

Two sets of test data were analyzed using the technique described above. The first set of data included spin losses where no external load was applied to the transmission other than the oil pumps connected to the accessory drive train. The second set of data simulated flight loading conditions.

\section{Spin Losses}

Figure 8 shows the gearbox spin losses as a function of input speed. In the analysis, gear torques were arbitrarily set to $22 \mathrm{~N}-\mathrm{m}$ ( 5 in-1bf) and bearing loads at $222 \mathrm{~N}$ (50 lbf) so that numerical expressions that have no value at zero load could be evaluated. It is apparent in Fig. 8 that the analysis gives an extremely good estimate of the spin losses. The range of measured values shown represents results obtained with different transmissions of the same design.

In Fig. 9 the losses are broken down analytically into four categories and shown as a function of gearbox input speed. Spin losses at full speed are listed by percentage in Table IV. The gear, bearing and oil pump losses are equally important at or near full speed. In the breakdown by component in Table IV the oil pump losses (one supply and two scavenge) were higher than any other single component. The high speed main drive gearset followed due mainly to the high windage losses. The accessory gear train which included the first two meshes and bearings had the third highest losses due to high windage losses (since the first mesh was actually a speed increase above input speed). The sum of these three sources amounted to 68.6 percent of all the spin losses of the transmission. This would be the area to investigate to reduce transmission spin losses since the remaining components contributed less than 6 percent each.

\section{Losses at Flight Loading Conditions}

Figure 10(a) shows the transmission losses as a function of input torque or power at a constant transmission input speed of $13820 \mathrm{rpm}$. This transmission is operated in a constant speed mode during flight conditions (see Table V). At zero speed the prediction agrees well as described above. The load sensitivity predicted by the present analysis is not as strong as that shown by the measured data. The prediction is low by $8.2 \mathrm{~kW}$ (11 hp) at takeoff power levels. This is equiva lent to 0.26 percentage points of efficiency. 
The data is replotted as efficiency in Fig. $10(\mathrm{~b})$. The analysis overestimates the measured efficiency by a nearly constant value over the operating range. There are several possible explanations for this; (1) experimental error, incorrect friction coefficient model for this lubricant or (3) lack of bearing load dependence.

Measurement of power loss in a very efficient transmission is a challenging task. The measured losses at full power are approximately $35 \mathrm{~kW}$ as compared to the input power level of $3132 \mathrm{~kW}$. In [7] a very thorough method of measuring heat rejection from a helicopter transmission was utilized to determine efficiency. The method included capturing the cooling water, weighing it and accurately recording temperature rise with an RTD thermocouple accurate to within 0.1 degrees $F$. The estimated accuracy of this technique at full rated power is plus or minus 0.1 percentage points. A similar technique was used to obtain this data but several modifications to the technique were utilized that decrease the accuracy of the measurement. From this viewpoint the predicted losses are within the experimental error of this type of test.

The gear friction coefficient model used in this analysis was based on a limited amount of lisc machine data run at typical gear contact conditions but at low siip rates[17]. It was intended to give an approximation of the friction coefficient for a given MIL-L-7808 oil in lieu of a more complete model. Some of the difficulties, as discussed earlier, in applying this limited disc machine friction data to gear power loss calculations will contribute to predictive inaccuracies. Also, operating temperatures in the T56/501 gearbox are generally much higher than those investigated in [17] and operating gear contact stresses are generally lower. It is anticipated that a more complete friction model would account for much of the load sensitivity disagreement encountered here.

The third possibility for the lack of predicted power loss load dependence could lie in the bearing power loss calculations. The large bearing programs used here, however, have been used in the past with good results. As a check, losses were also calculated with the Harris Eq. [16] and found to show even less load dependence overall. Bearing losses are not likely to be the source of the lower predicted losses at the more heavily loaded condition.

Despite these sources of inaccuracy, the predicted efficiency trends with input power closely match the measured data in Fig. 10(b). Based on this power loss prediction model, the losses were analyzed by category and component in Fig. 11 to 17 and in Table IV. In Fig. 11 the losses are shown by general category. The total system bearing loss is somewhat greater than the total gear loss over the range of operating conditions. As mentioned before, oil pump losses are a very significant part of the system loss. The accessory drive (gears and bearings) losses are a smaller but significant portion of the transmission losses.

In Fig. 12 the individual transmission bearing losses are shown as a function of power level.
The very modest increase in bearing loss with load can be seen. 0nly the spherical planet bearing shows a stronger load dependence. Its affect on the transmission loss is greater than shown here since this loss must be multiplied by five since there are five planet bearings in the transmission. The propeller radial and thrust bearing losses are very low due to the relatively low rotational speed.

A comparison of the losses in the main drive gears and the planetary gearset is shown in Fig. 13. The planetary gearset has only half the loses at full power due to its lower operating velocities and lack of windage losses even though both are carrying approximately the same power. The planetary action of the carrier is beneficial in reducing contact velocities in the gear mesh. Calculated as efficiency the main drive has an efficiency of 99.86 percent at full power and the planetary has an efficiency of 99.93 percent. These values are quite high and are due mainly to the low coefficient of friction of the MIL-L-7808 oil.

The transmission losses at full power are shown by component in Table IV. At full power the oil pumps are again the single largest contributor to the gearbox loss. The main drive gears are next followed by the planet bearing. These three components alone make up 45 percent of the losses for the whole transmission at full load.

If an improvement in efficiency is required these components should be investigated first due to this significant impact on overall efficiency. All other components contribute less than 7 percent each.

\section{Summary}

A previously developed method for calculating efficiency of spur gears was extended to include planetary gearsets. A friction coefficient model was developed for a MIL-L-7808 type oil based on disc machine friction data. Power loss of a complete T56/501 gearbox was determined using these methods in conjunction with both the Harris bearing power loss expressions and large scale bearing computer programs. The following results were obtained:

(1) Gearbox spin loss predictions to $13820^{\circ}$ rpm agreed well with measured data.

(2) Gearbox losses at flight conditions were underestimated resulting in a gearbox efficiency prediction that was approximately 0.3 percentage points above the measured data over the operating range. This difference is within the experimental accuracy of the measurement and the anticipated accuracy of the friction model emp loyed.

(3) The planetary gearset had approximately half the losses of the high speed external main drive mesh even though both were carrying approximately $3132 \mathrm{~kW}(4200 \mathrm{hp})$.

(4) Losses in the oil pumps were a major portion of both the spin and full power losses. 


\section{References}

1. Shipley, E. E., "Loaded Gears in Action," Gear Handbook, D. W. Dudley, ed., McGraw Hi11, Inc., 1962, pp. 14-1 to 14-60.

2. Buckingham, E., "Efficiencies of Gears," Analytical Mechanics of Gears," Dover Publications, 1963, pp. 395-425.

3. Anderson, N. E., and Loewenthal, S. H. "Spur-Gear-System Efficiency at Part and Fu11 Load," NASA TP-1622, AVRADCOM TR 79-46, 1980.

4. Anderson, N. E., and Loewenthal, S. H., "Design of Spur Gears for Improved Efficiency," ASME Journal of Mechanical Design, Vol. 104, 0ct. 1982, pp. 767-774.

5. Anderson, N. E., and Loewenthal, S. H., "Efficiency of Nonstandard and High Contact Ratio Involute Spur Gears," to be presented at the Fourth International Power Transmission and Gearing Conference, Oct. 1984.

6. Benedict, G. H., and Kelley, B. W., "Instantaneous Coefficient of Gear Tooth Friction," ASLE Transactions, Vol. 4, No. 1, Aprl. 1961, pp. 59-70.

7. Mitche1], A. M., "Lubricant Effects on Efficiency of a Helicopter Transmission," NASA TM-82857, American Helicopter Society paper No. AHS-RWP-15. (See also AVRADCOM TR-82-C-9).

8. Crook, A. W., "The Lubrication of Rollers. IV - Measurements of Friction and Effective Viscosity," Philisophical Transactions of the Royal Society (London), sen. A, Vol. 255 , No. 1056 , Jan. 1963 , pp. 281-312.

9. Hamrock, B. J., and Dowson, D., "Isothermal Elastohydrodynamic Lubrication of Point Contacts. III - Fully Flooded Results," ASME Journal of Lubrication Technology, Vol. 99, No. 2, Apr. 1977, pp. 264-276.

10. Cheng, H. S., "Prediction of Film Thickness and Sliding Frictional Coefficients in Elastohydrodynamic Contacts," ASME Design Engineering Technology Conference, ASME, New York, 1974, pp. 286-293.

11. Khiralla, T. W., On the Geometry of External Involute Spur Gears, C/I Leaming, North Hollywood, Calif., 1976.
12. Glover, J. H., "Efficiency and Speed Ratio Formulas for Planetary Gear Systems," Product Engineering, Sept. 27, 1965.

13. Kleckner, R. J., and Pirvics, J., "High Speed Cylindrical Roller Bearing Analysis (CYBEAN) Users's Manual," SKF Report No. AL78P023, SKF Industries, Inc. (NASA Contract No. NAS3-22807), July, 1978.

14. Kleckner, R. J., Dyba, G. J., and Ragen, M. A., "Spherical Roller Bearing Analysis (SPHERBEAN) User's Manual," SKF Report No. AT81D007, SKF Industries, Inc. (NASA Contract NAS3-22807), Feb. 1982.

15. Hadden, G. B., Kleckner, R. J., Ragen, M. A., and Sheynin, L., "System Including Ball, Cylindrical, and Tapered Roller Bearings (SHABERTH) User's Manual," SKF Report No. AT810040, SKF Industries, Inc. (NASA Contract No. NAS3-22690), May, 1981 .

16. Harris, T. A., "Rolling Bearing Analysis. John Wiley and Sons, Inc., 1966, pp. 446-450.

17. Walowitt, J. A., "Traction Characteristics of a MIL-L-7808 0il," ASME Paper 76-LubS-19 1976.

18. Gupta, P. K., Flammand, L., Berthe, D., and Godet, M.: "On the Traction Behavior of Several Lubricants," ASME paper 80-C2/Lub-15, 1980.

19. Johnson, K. L., and Greenwood, J. A. "Thermal Analysis of an Eyring Fluid in Elastohydrodynamic Traction," Wear, Vol. 61, 1980, pp. 353-374.

20. Tevaarwerk, J. L., "Traction in Lubrication Contacts," Proceedings of International Symposium on Contact Mechanics and Wear of Rail/ Wheel Systems. Vancouver, Canada, July 6-9, 1982 .

21. Jeffries, J. A., and Johnson, K. L., "Sliding Friction Between Lubricated Rollers," Traction in Elastohydrodynamic Contacts, Proceedings of Institution of Mechanical Engineers, Vol. 182, pt. 1, No. 4, 1967-68. 


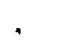


TABLE I. - TEST LUBR ICANT TYPES

\begin{tabular}{|c|c|c|}
\hline Code & Specification & Type \\
\hline $\begin{array}{l}A \\
B \\
C \\
D \\
E \\
F \\
G \\
H \\
I \\
\text { J } \\
K\end{array}$ & $\begin{array}{l}\text { Dexron II GM } 6137-M \\
\text { Dexron II GM } 6137-M \\
\text { MIL-L-23699 } \\
\text { MIL-L-23699 } \\
\text { MIL-L-2104C } \\
\text { MIL-L-46152 } \\
\text { MIL-L-7808 } \\
\text { MIL-L-23699 } \\
\text { MIL-L-23699 }\end{array}$ & $\begin{array}{l}\text { Automatic Transmission Fluid } \\
\text { Automatic Transmission Fluid } \\
\text { Turbine Engine 0il } \\
\text { Type II Synthetic Gas Turbine Engine 0il } \\
\text { Type I Synthetic Gear Lubricant } \\
\text { Synthetic Paraffinic with Antiwear Additives } \\
\text { Synthetic Fleet Engine 0il } \\
\text { Turbine Engine 0il } \\
\text { Type II Turbine Engine 0il } \\
\text { Type II Turbine Engine 0i1 } \\
\text { Turbine Engine 0i1 }\end{array}$ \\
\hline
\end{tabular}

TABLE II. - T56/501 GEARS;

PRESSURE ANGLE $=25^{\circ}$,

DIMETRAL PITCH $=6$

\begin{tabular}{|l|r|}
\hline \multicolumn{1}{|c|}{ Gear } & Number of teeth \\
\hline Main drive pinion & 32 \\
Main drive gear & 100 \\
Sun gear & 30 \\
Planet & 35 \\
Ring gear & 100 \\
\hline
\end{tabular}

TABLE III. - T56/501 BEARINGS

\begin{tabular}{|l|c|l|}
\hline Location & Bore, $\mathrm{mm}$ & \multicolumn{1}{|c|}{ Type } \\
\hline Pinion - front & 75 & Cylindrical \\
Pinion - rear & 55 & Cylindrical \\
Main drive & 160 & Cylindrical \\
Carrier support & 160 & Cylindrical \\
Prop radial & 125 & Cylindrical \\
Prop thrust & 125 & Angular contact bal1 \\
Planet & $97^{\star}$ & Spherical \\
\hline
\end{tabular}

$\star$ * itch diameter. 
TABLE IV. - RANKING OF GEARBOX LOSSES

\begin{tabular}{|c|c|}
\hline $\begin{array}{l}\text { Spin losses } \\
\text { at full speed }\end{array}$ & $\begin{array}{l}\text { Losses at } \\
\text { full power }\end{array}$ \\
\hline $\begin{array}{l}\text { 1. Gears, Bearings, } 0 i 1 \\
\text { Pumps }-25 \text { to } 30 \text { percent each } \\
\text { 2. Accessory Drive - } 14 \text { percent }\end{array}$ & $\begin{array}{l}\text { 1. Bearings }-37 \text { percent } \\
\text { 2. Gears }-31 \text { percent } \\
\text { 3. 0i1 Pumps }-21 \text { percent } \\
\text { 4. Accessory Drive }-10 \text { percent }\end{array}$ \\
\hline \multicolumn{2}{|c|}{ Breakdown by Component, percent } \\
\hline $\begin{array}{l}29.3 \text { 0i1 Pumps } \\
26.8 \text { Main Drive Gears } \\
12.5 \text { Accessory Gears } \\
68.6 \text { percent }\end{array}$ & $\begin{array}{l}16.1 \text { 0i1 Pumps } \\
15.4 \text { Main Drive Gears } \\
13.5 \text { Planet Bearing } \\
\mathbf{4 5 . 0} \text { percent }\end{array}$ \\
\hline $\begin{array}{ll}5.7 & \text { Carrier Bearing } \\
5.6 & \text { Pinion Front Bearing } \\
5.3 & \text { Main Drive Bearing } \\
5.1 & \text { Planet Bearing } \\
2.6 & \text { Pinion Rear Bearing } \\
2.6 & \text { Planet/Ring Gear Mesh } \\
2.2 & \text { Sun/Planet Gear Mesh } \\
1.7 & \text { Accessory Bearings } \\
.3 & \text { Prop. Radial Bearing } \\
.3 & \text { Prop. Thrust Bearing }\end{array}$ & $\begin{aligned} 6.8 & \text { Accessory Gears } \\
6.8 & \text { Sun/Planet Gear Mesh } \\
4.9 & \text { Pinion Front Bearing } \\
3.8 & \text { Main Drive Bearing } \\
3.3 & \text { Carrier Bearing } \\
1.7 & \text { Pinion Rear Bearing } \\
.9 & \text { Accessory Bearings } \\
.9 & \text { Planet/Ring Gear Mesh } \\
.2 & \text { Prop. Radial Bearing } \\
.1 & \text { Prop. Thrust Bearing }\end{aligned}$ \\
\hline
\end{tabular}

TABLE V. - POWER LEVELS AT FLIGHT CONDITONS; CONSTANT INPUT SPEED $=13820 \mathrm{rpm}$

\begin{tabular}{|c|c|}
\hline Flight condition & Power level, kW \\
\hline Descent & 945 \\
Cruise & 1516 \\
Climb & 2461 \\
Takeoff & 3132 \\
\hline
\end{tabular}




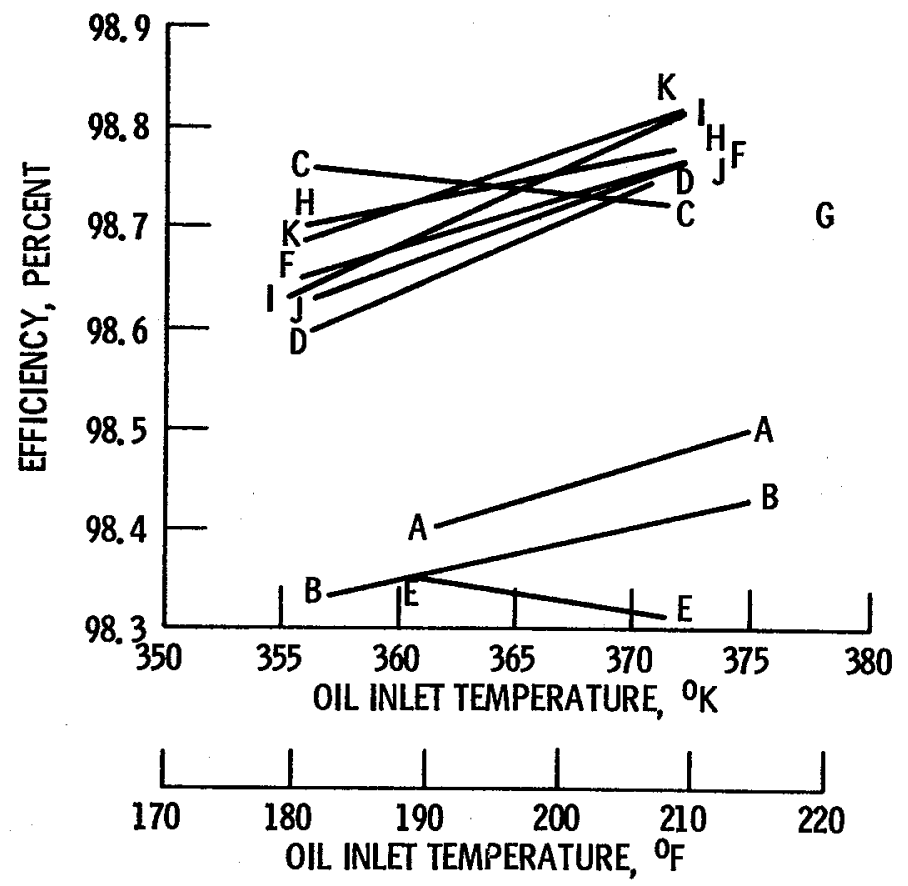

Figure 1. - Variation in gearbox efficiency for eleven different oils defined in Table I. from [7]. 


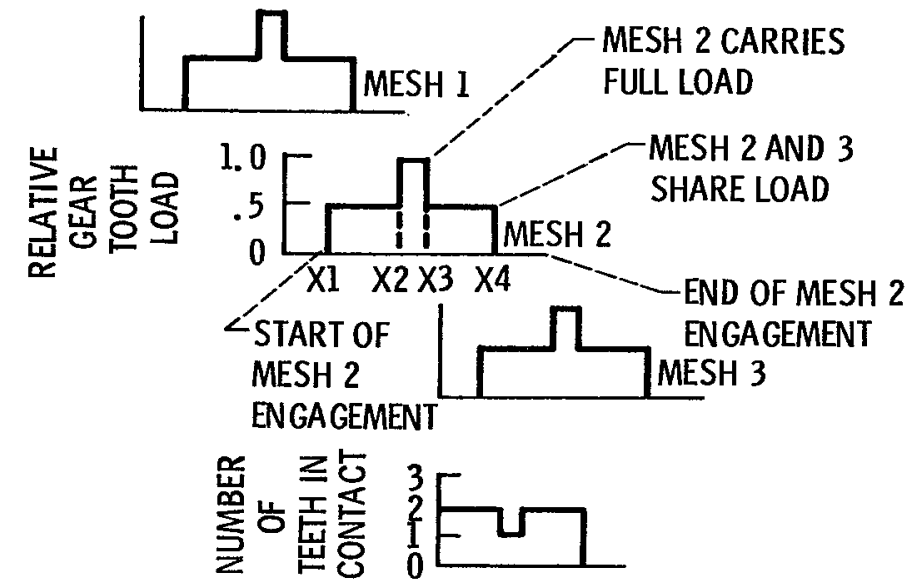

(a) Contact ratio between one and two.
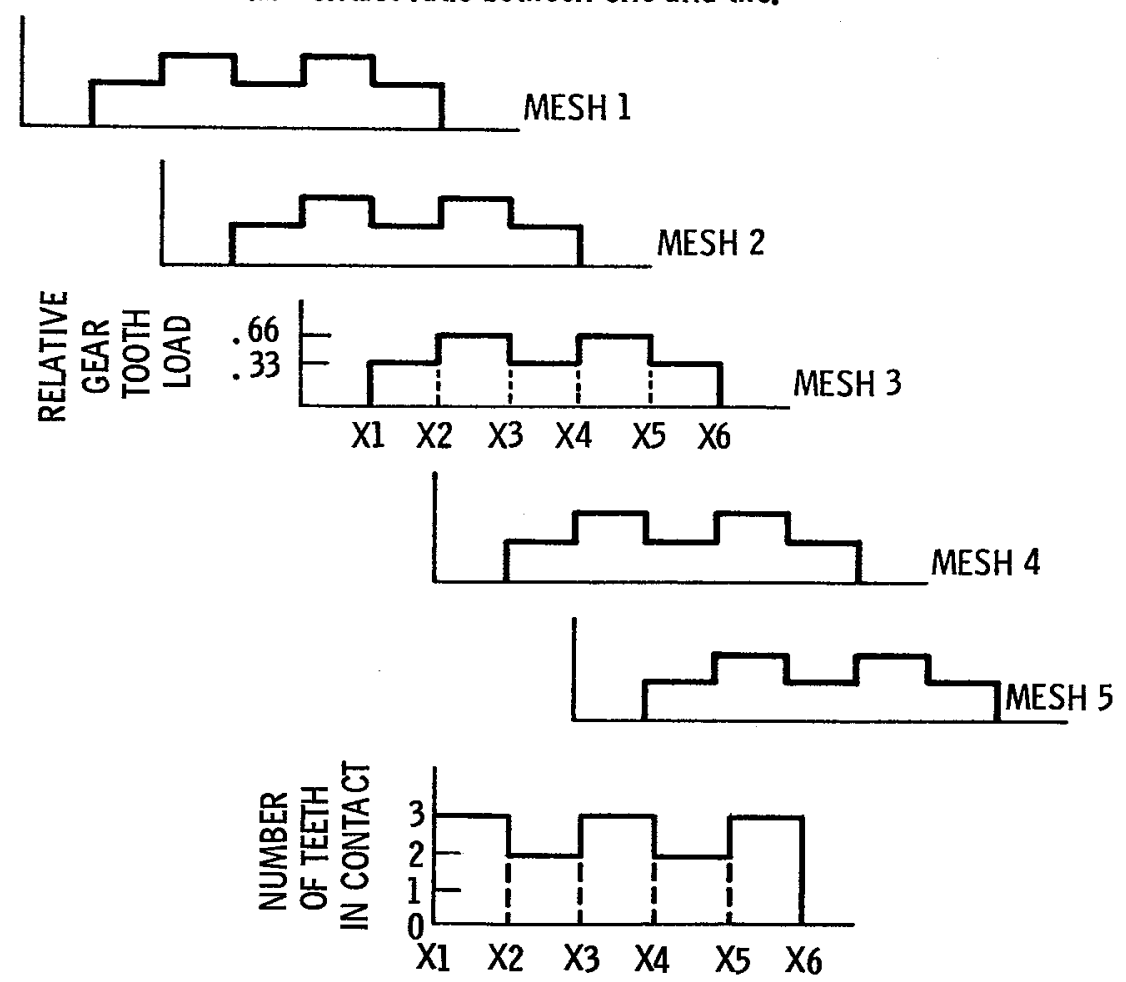

(b) Contact ratio between two and three.

Figure 2. - Tooth normal load distribution. 


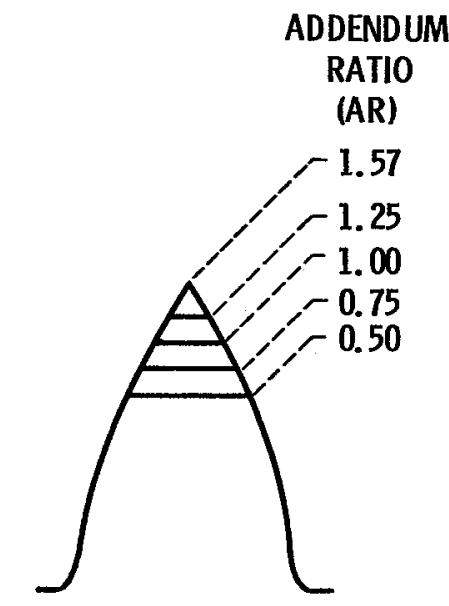

(a) Modified with addendum ratio.

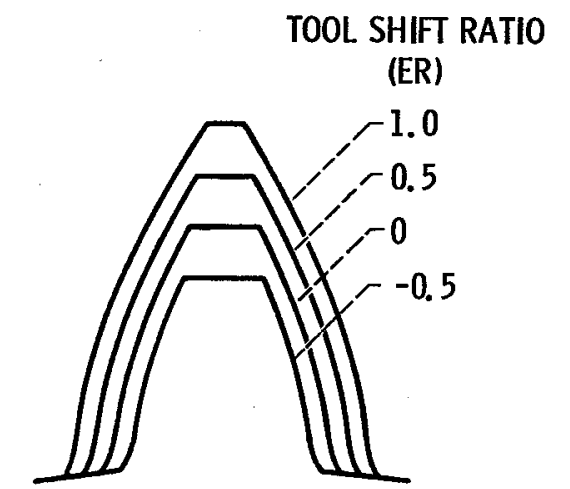

(b) Modified with tool shift

Figure 3. - Non-standard gear tooth shapes. 

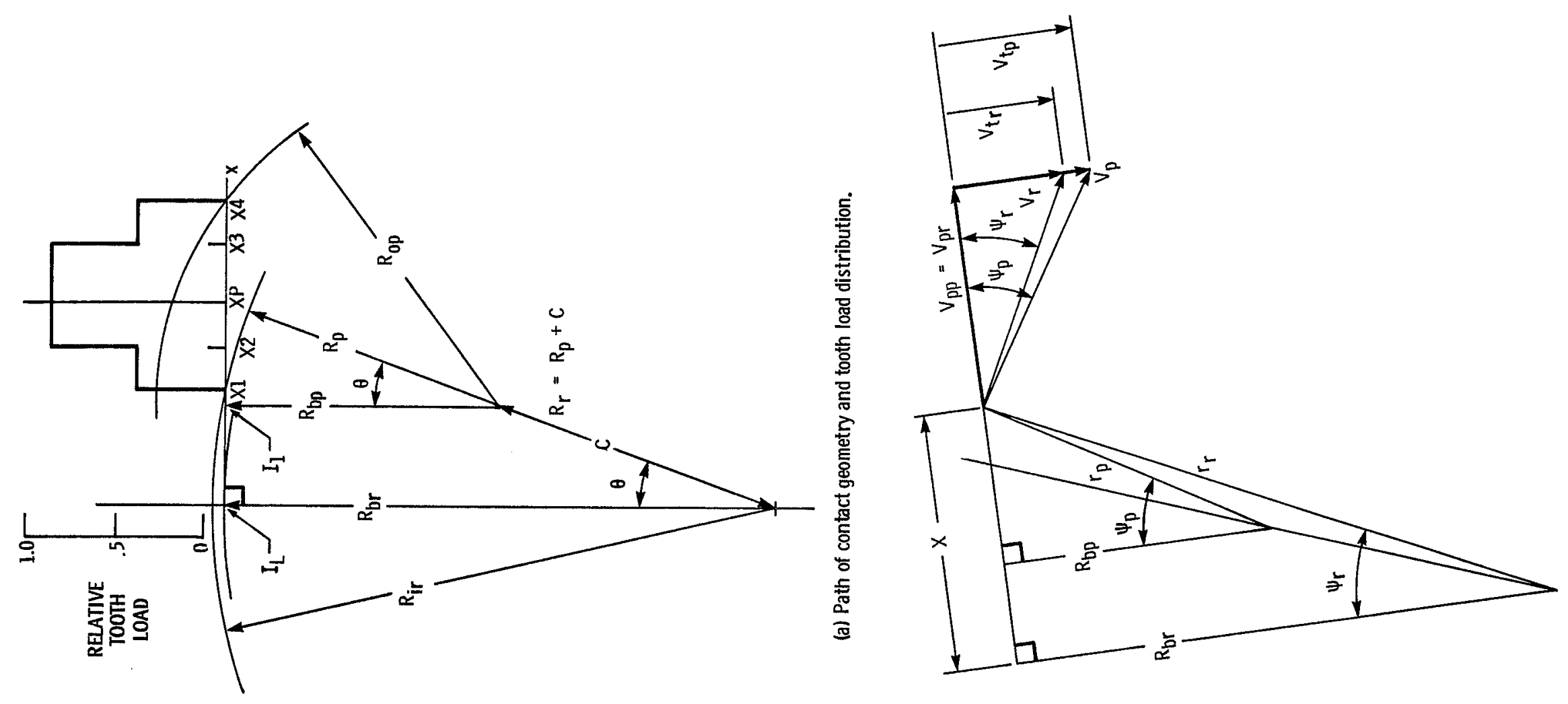

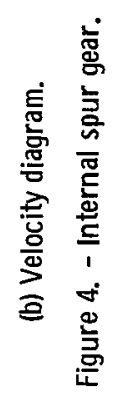




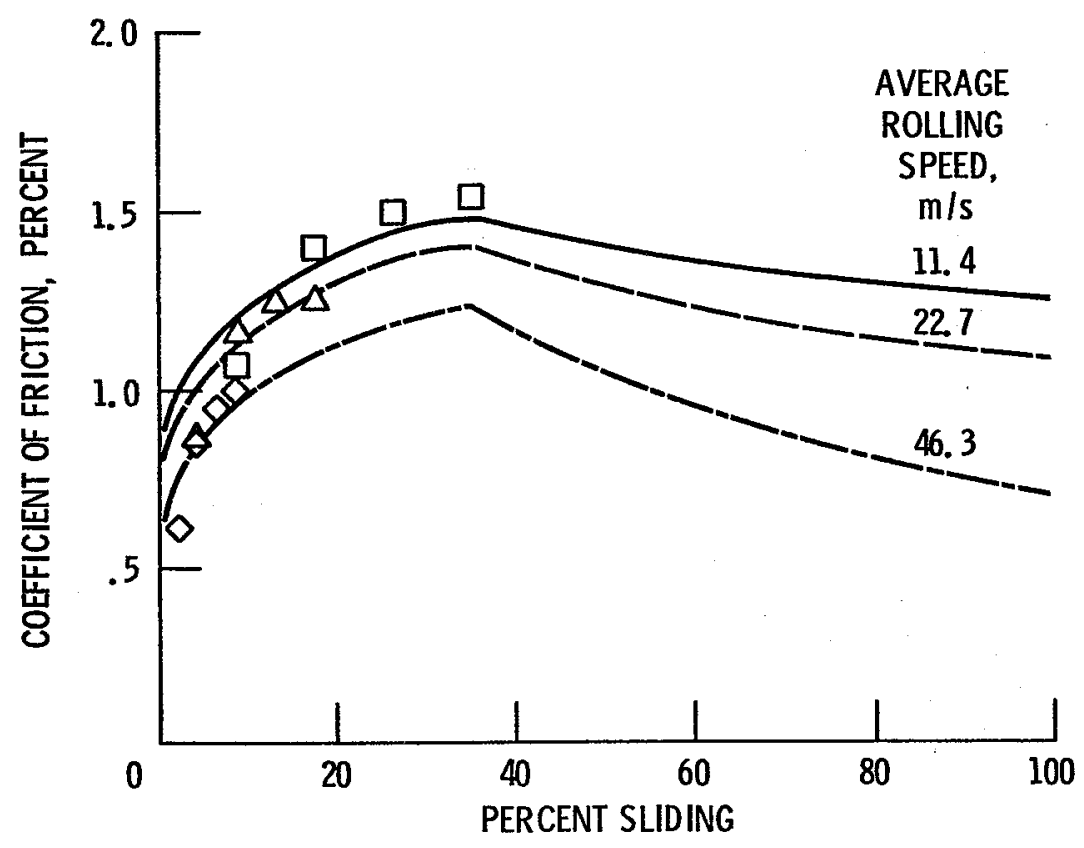

Figure 5. - Comparison of regression analysis (eq. 21, 22) with test data of [17] for MIL-L-7808 oil。

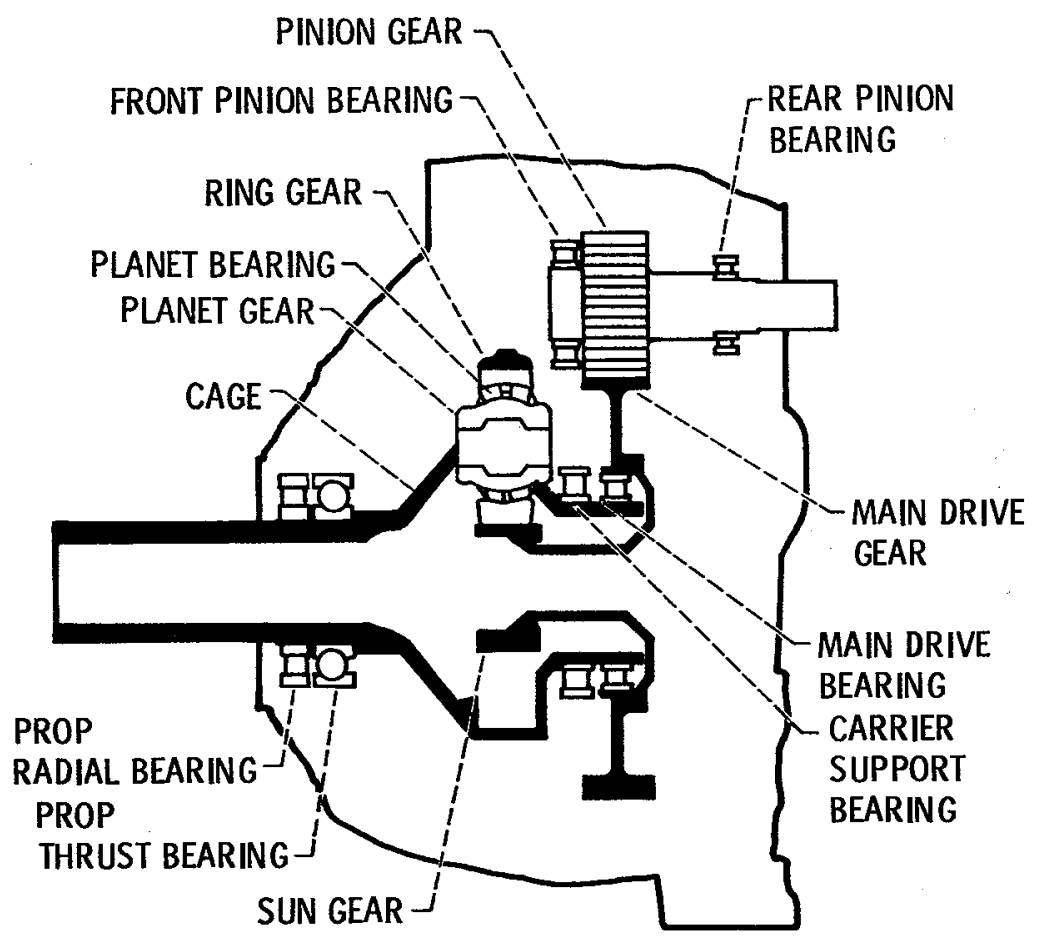

Figure 6. - T-56 gearbox arrangement. 


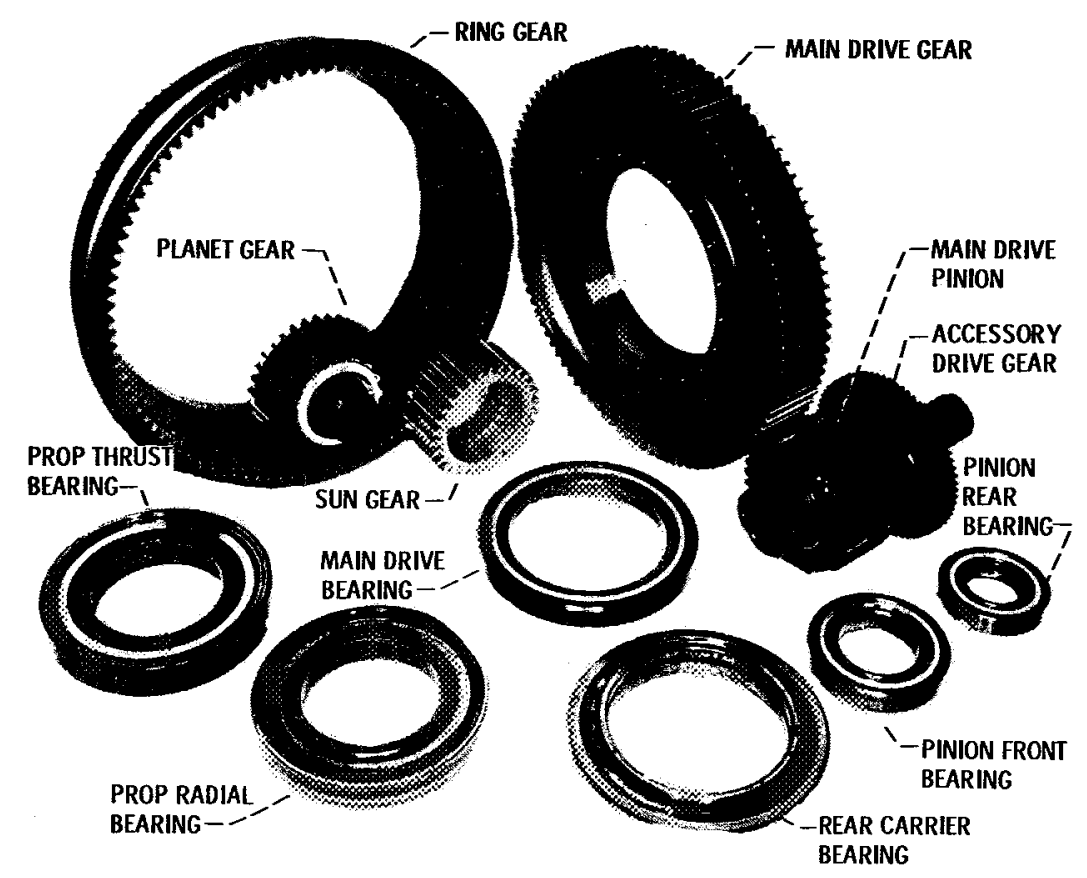

Figure 7. - T56/501 gears and bearings.

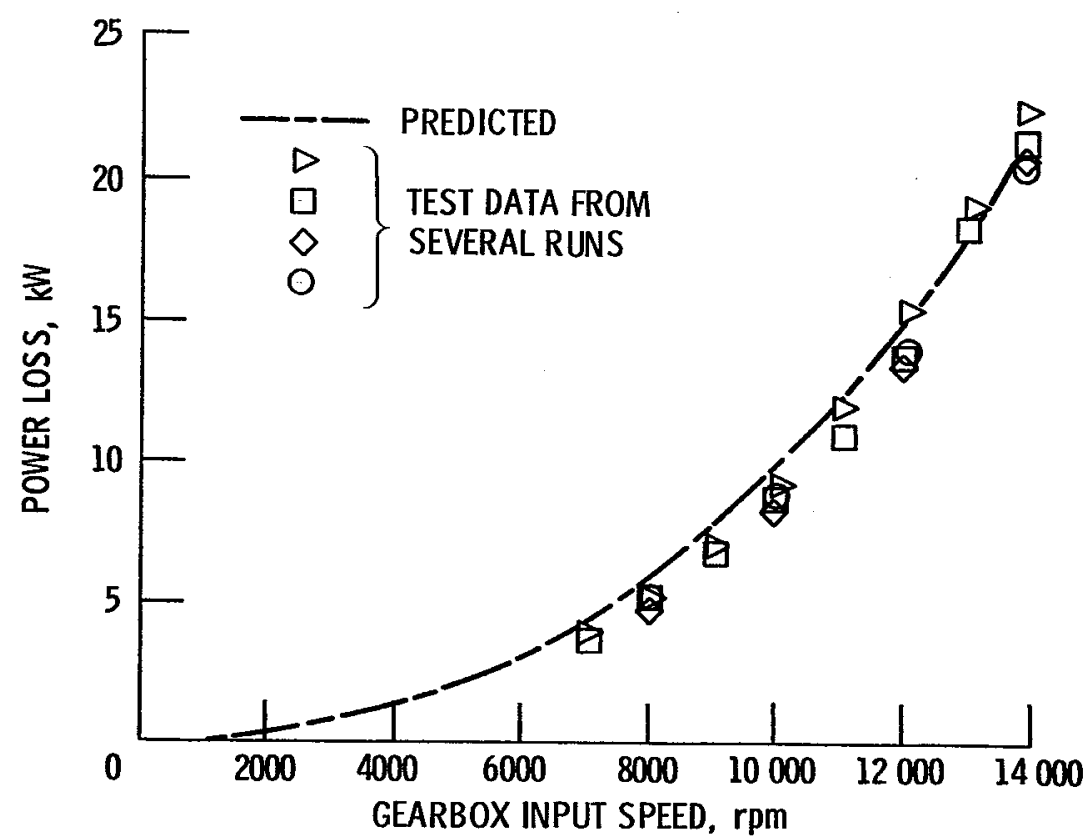

Figure 8. - Gearbox tare losses as a function of input speed. 


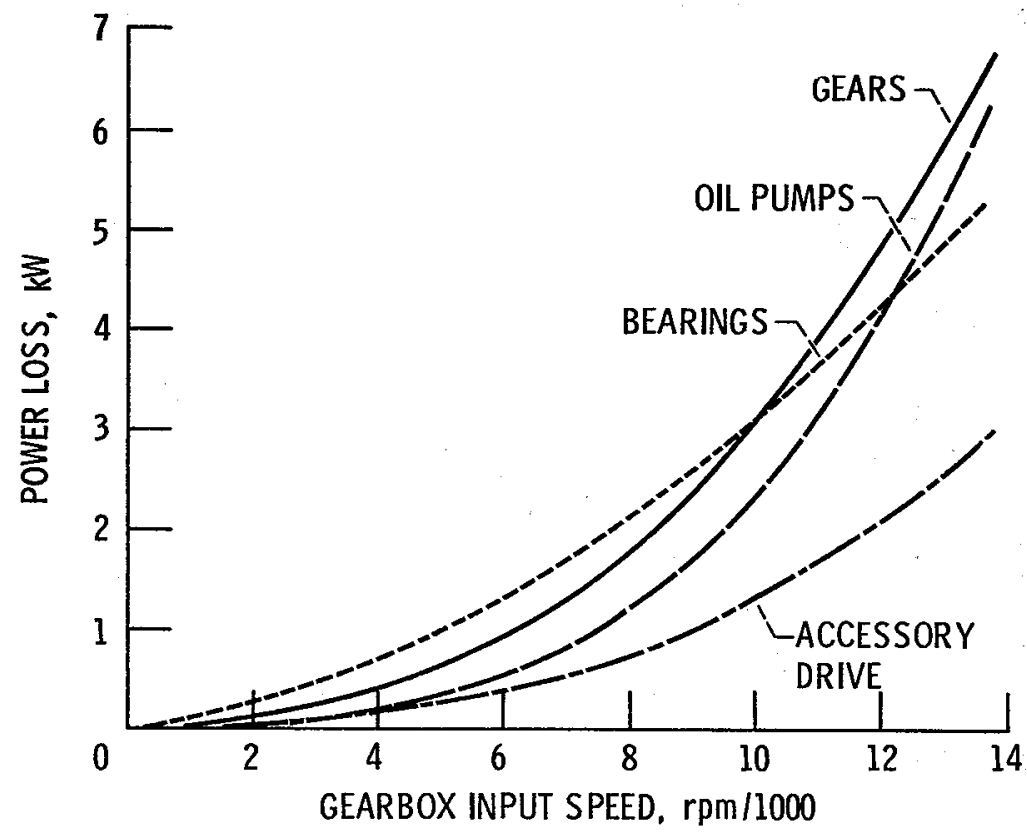

Figure 9. - Analytical breakdown of gearbox tare losses as a function of input speed. 


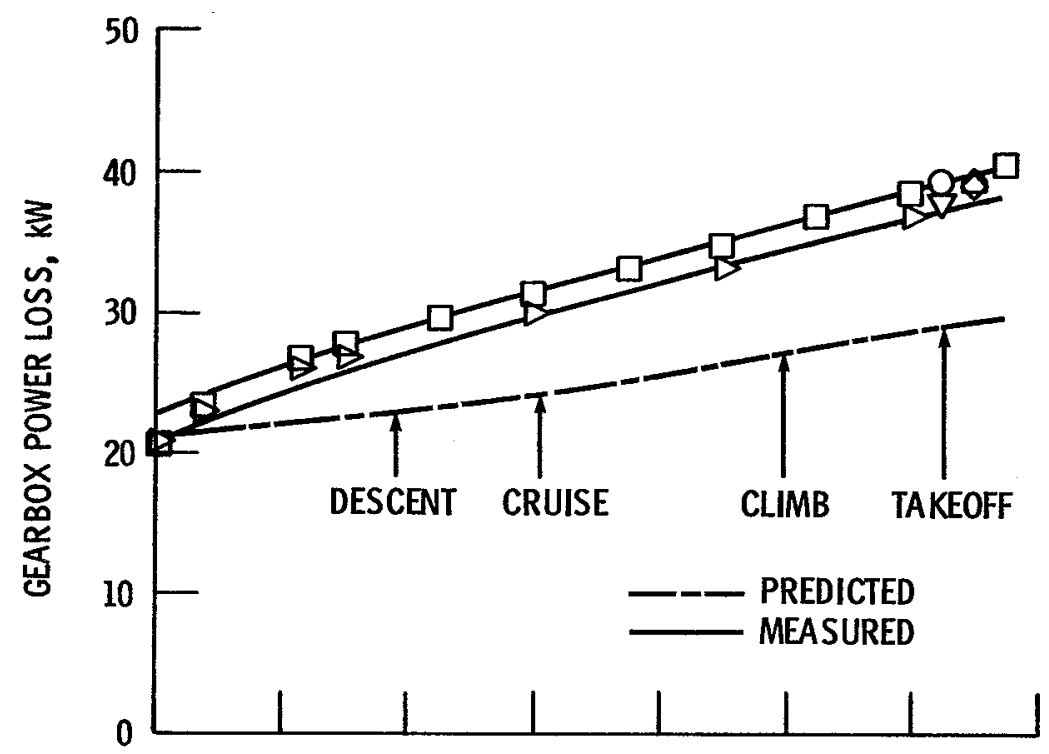

(a) Power loss.

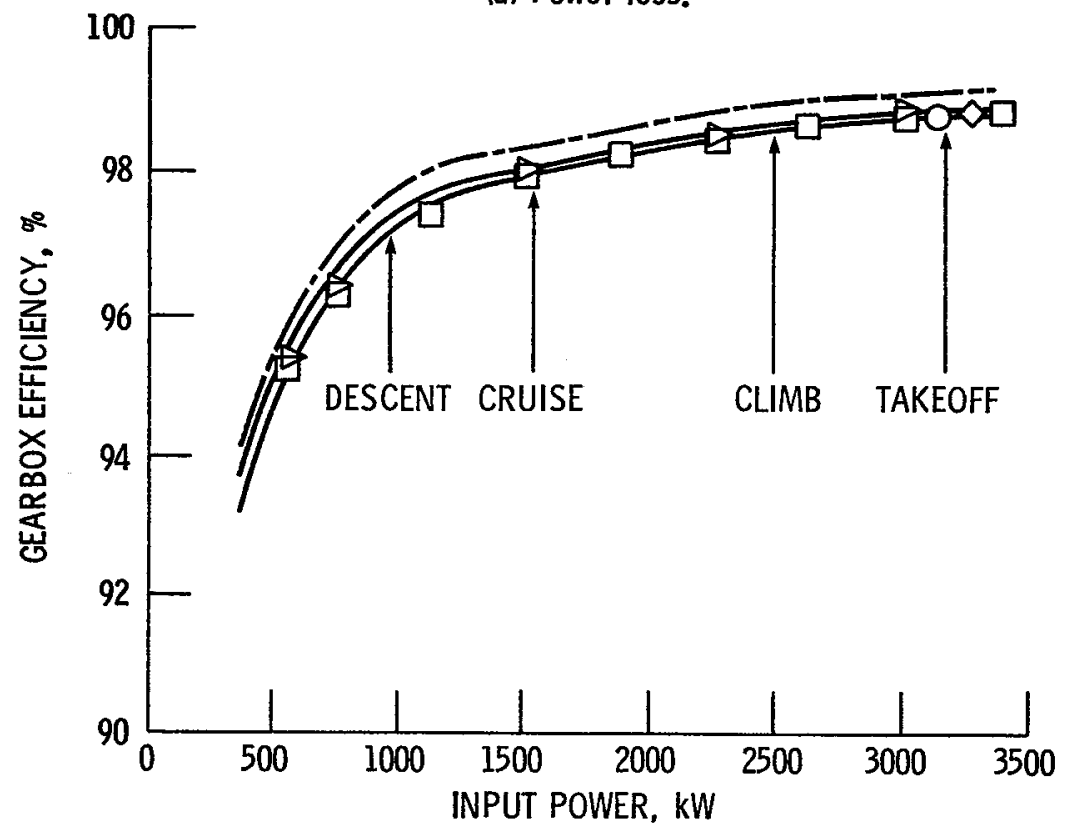

(b) Efficiency.

Figure 10. - Gearbox losses as a function of transmitted power at full input speed $=13820 \mathrm{rpm}$. 


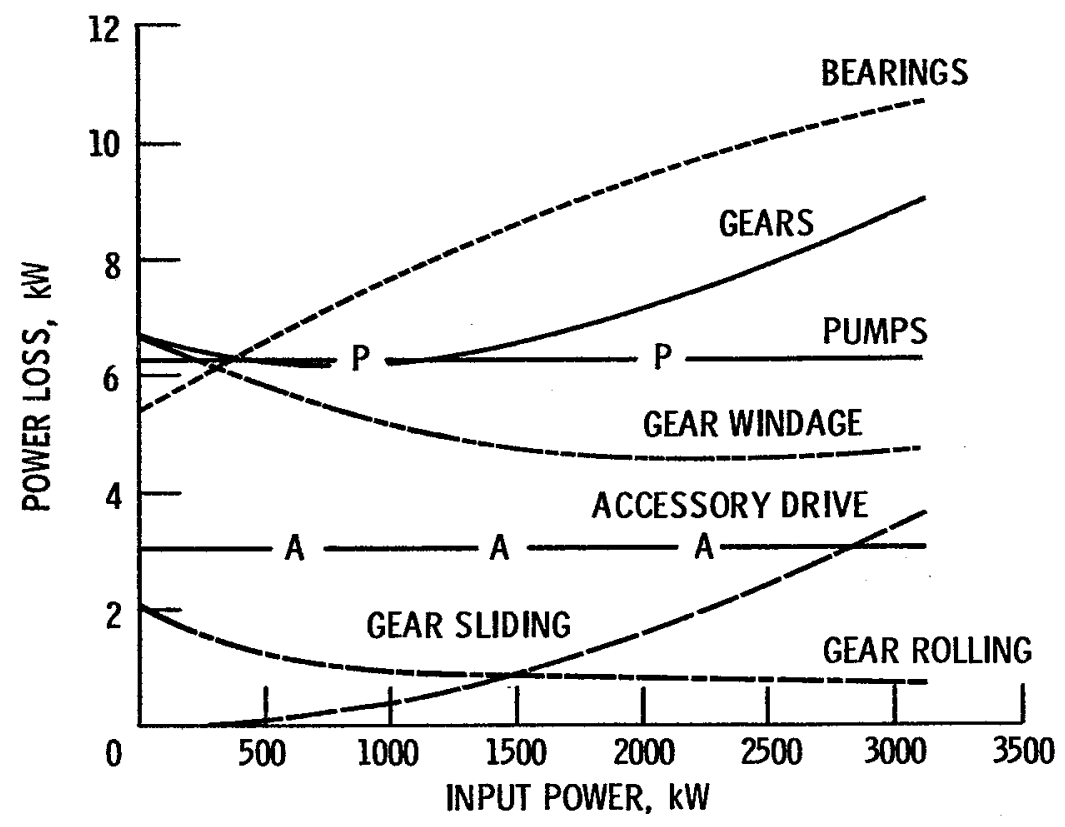

Figure 11. - Analytical breakdown of gearbox losses as a function of input power at full input speed $=13820 \mathrm{rpm}$.

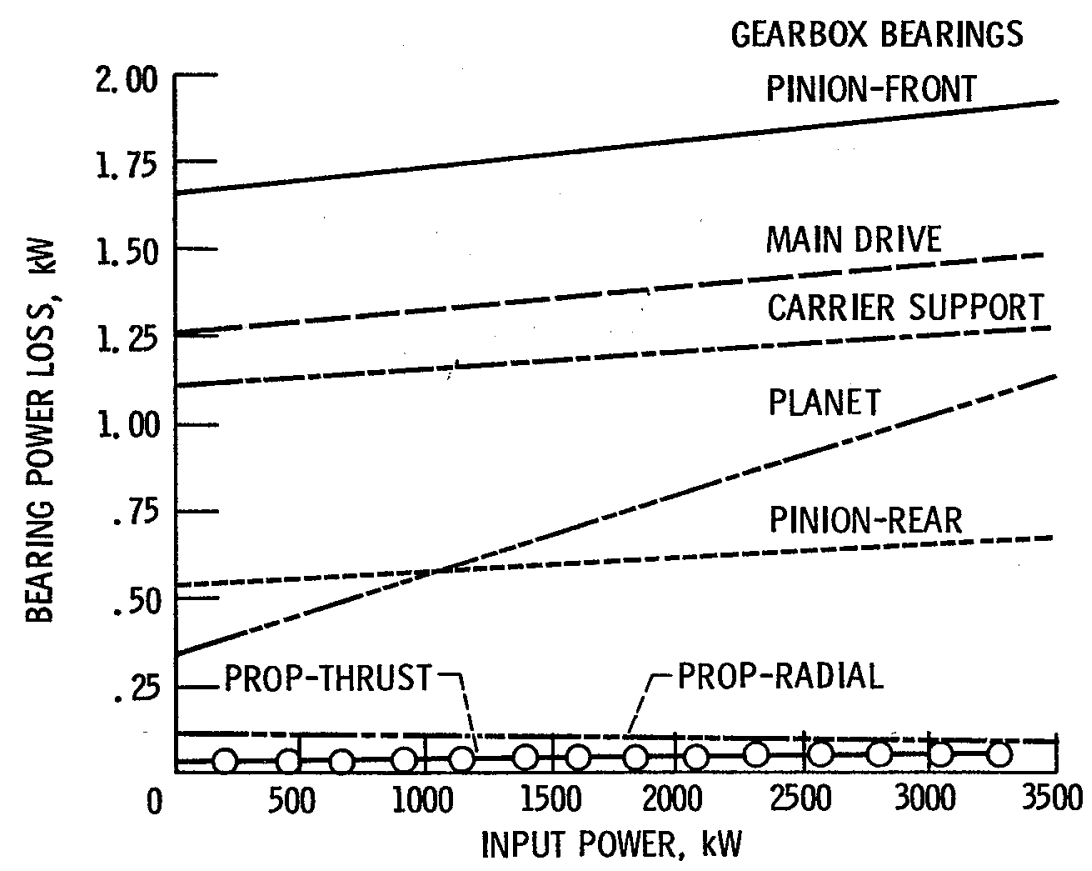

Figure 12. - Analytical breakdown of bearing losses as a function of input power at full input speed $=13820 \mathrm{rpm}$. 


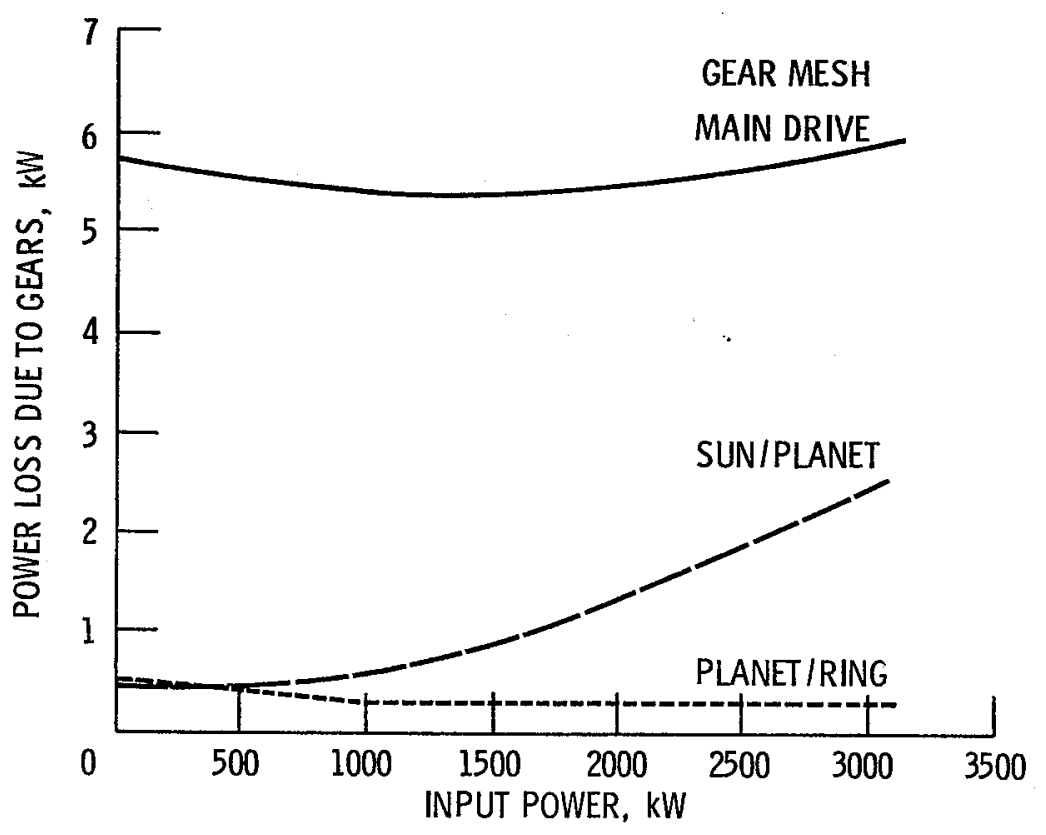

Figure 13. - Analytical breakdown of gear losses as a function of input power at full input speed $=13820 \mathrm{rpm}$. 
- 


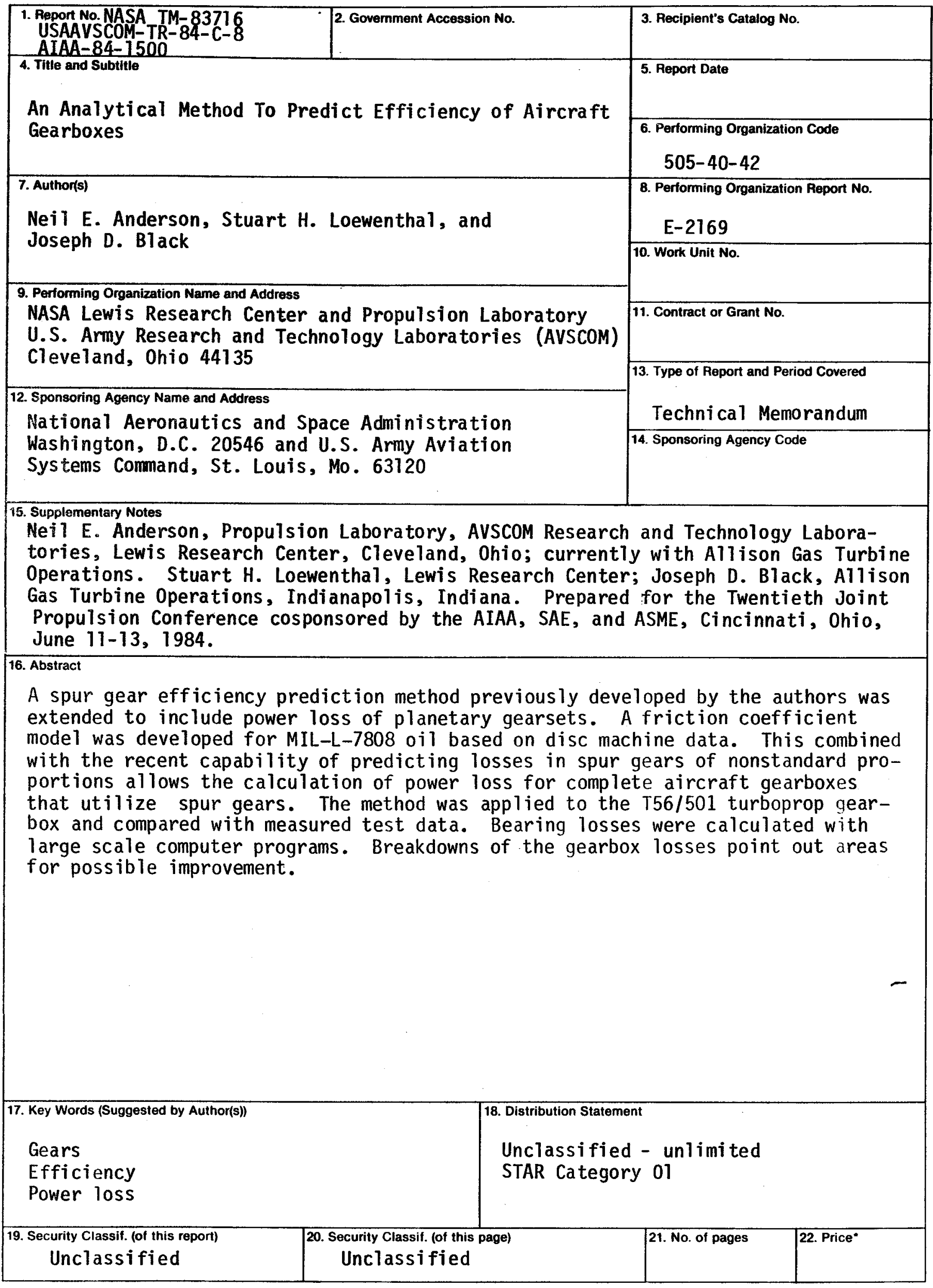

"For sale by the National Technical Information Service, Springfield, Virginia 22161 